University for Business and Technology in Kosovo

UBT Knowledge Center

UBT International Conference

2018 UBT International Conference

Oct 27th, 1:30 PM - 3:00 PM

\title{
Nursing Care in Children with Type 1 Diabetes Mellitus
}

Doruntina Ismaili

University for Business and Technology, ismailidoruntina@gmail.com

Fëllënza Spahiu

University for Business and Technology

Lirije Beqiri

University for Business and Technology

Afërdita Berisha

University for Business and Technology

Follow this and additional works at: https://knowledgecenter.ubt-uni.net/conference

Part of the Medicine and Health Sciences Commons

\section{Recommended Citation}

Ismaili, Doruntina; Spahiu, Fëllënza; Beqiri, Lirije; and Berisha, Afërdita, "Nursing Care in Children with Type 1 Diabetes Mellitus" (2018). UBT International Conference. 370.

https://knowledgecenter.ubt-uni.net/conference/2018/all-events/370

This Event is brought to you for free and open access by the Publication and Journals at UBT Knowledge Center. It has been accepted for inclusion in UBT International Conference by an authorized administrator of UBT Knowledge Center. For more information, please contact knowledge.center@ubt-uni.net. 


\title{
Nursing Care in Children with Type 1 Diabetes Mellitus
}

\author{
MSc. Doruntina ISMAILI ${ }^{1}$, MSc. Fëllënza SPAHIU², MSc. Lirije BEQIRI ${ }^{2}$, MSc. Afërdita BERISHA² \\ ${ }^{1}$ (Author) and ${ }^{2}$ (Coauthor) -Educators in health care \\ UBT-Higher Education Institution, Lagjia Kalabria, 10000 p.n., Prishtinë. Kosovo \\ ismailidoruntina@gmail.com, fllazaspahiu@gmail.com, lirijebeqiri@yahoo.com, afro_leka@hotmail.com
}

\begin{abstract}
A life dependent from insulin certainly requires patience, support, care and a constant education from our side as professionals of medicine toward our patients who are affected by diabetes. The prevalence of this disease is increasing, whereas the incidence is approximately 4 cases per 100000 inhabitants. Factors that affect this disease are many, ranging from the genetic basis to stress and trauma. The complications of this are inevitable that touch almost the whole system and bodies starting from the brain to the legs.

Based on the research conducted the total number of children with type 1 diabetes mellitus in the endocrinology department at the Pediatric Clinic in Prishtina during the 5 year period from 2012 -2016, in totally there are 386 new cases, 183 are females and 185 are males, we have concluded that urban areas are the most affected by rural areas, gender is affected by almost both sexes, while age groups are: females are born between 2001 and 2015, while men range between 2004 and 2016.

Education - Periodic control of glucose reduces hyperglycemia complications. For the self-treatment of insulin, the nurse should educate the child in light of his age. They are explained where and how to inject insulin, injection angle, then education for bodily activities, diet and maintaining personal hygiene (foot care).
\end{abstract}

Key words. : Type 1 Diabetes mellitus, insulin, research, education. 


\section{INTRODUCTION}

According to the World Health Organization (WHO), diabetes is defined as a condition of chronic hyperglycemia, determined by genetic and environmental factors. Type 1 diabetes belongs to the most common chronic endocrine disorder of children. Type 1 diabetes is an autoimmune syndrome that destroys pancreatic beta cells and is characterized by the almost complete absence of insulin secretion from the endocrine pancreas. Autoimmune Disorder is a disorder in which the immune system of the body, which normally protects the body against foreign invaders, incorrectly identifies part of the body as a foreigner and attacks healthy tissue. The disease is due to lack of insulin, which leads to carbohydrate, fat, and protein metabolism disorders with typical clinical presentation. Insulin is the main anabolic hormone in the body. The main feature of diabetes in children is insulin dependence. The main reason for this is the absolute lack of insulin. The stages of the disease are: 1. Prediabetes- is the period from the beginning of the process to the possible occurrence of the first abnormalities in carbohydrate metabolism in children, 2. Subclinical Diabetes - Carbohydrate metabolism is only disrupted in the event of infections, caries, trauma or surgery, 3. Diabetes patients who are ill at this stage of the disease are without any symptoms, rarely have normal glucose levels in the blood, but hyperglycemia occurs after food intake or after oral glucose loading, 4. Diabetes manifestations of children appear swiftly, while switching from latent stage to manifest is provoked by infections, traumas, and surgical interventions. Symptoms and clinical signs of the disease start due to the difficult use of glucose in cells due to lack of insulin. Lack of insulin results in blood glucose collection (hyperglycemia). When the blood glucose concentration exceeds the maximum kidney transplant (about $9.0 \mathrm{mmol} / \mathrm{L}$ ), glucose begins to appear in the urine (glucose). Glucose in the urine draws water by increasing the volume of urine and frequent urination (polyuria). Increasing the loss of fluid with urine causes an increased and permanent thirst for the patient, which he tends to compensate for by adding juices (polydipsia). The overall lack of energy consequently has subjective feeling of hunger and increased food intake (polyphagia), but with no effect, which consequently has a growing stagnation, weakening (loss of body mass) to cachexia in unidentified cases, not well-cared for melitic type 1 diabetes. Diagnosis of type 1 diabetes mellitus is confirmed by the presence of glucose and hyperglycemia above $6.6 \mathrm{mmol} / \mathrm{L}(120 \mathrm{mg} \%)$ in soma or above $8.8 \mathrm{mmol} / \mathrm{L}$ (160 mg\%) after food. In ketoacidosis, the acetone test in urine is positive and other acidosis lab tests. Blood glucose hemoglobin (HbA1C) is over 8\% (proportional to the amount of glucose in the blood). The complications of type 1 diabetes mellitus can be: acute and chronic. Acute complications - The most important acute diabetes mellitus type 1 complications are: hypoglycemia and diabetic ketoacidosis. While chronic complications appear after several years (10-20 years) from the onset of the disease. Chronic complications are: Angiopathy, Diabetic Nephropathy, Neuropathy, Diabetic Retinopathy, Bleeding in the Eye Glass, Macrovascular Diseases. The purpose of the medication is normalization of blood glucose and of all metabolic processes in the body, which are mediated by insulin. Insulin delivery, rigorous diet, physical activity, hygiene, preservation from infections and complications will be the whole type 1 diabetes medication. Insulin is the basic treatment for diabetes. It is used through subcutaneous injections or insulin pump,

along with dietary management, including carbohydrate monitoring and blood glucose control, using glucose meters. Administered via subcutaneous and intravenous routes. Eliminated through the urine and the balance. There are some insulin forms; insulin with short, medium and long acting. It is preferred to combine these forms. The injection site changes after each injection line, it also affects the duration of the start of the action; abdomen (fast), upper arm (slowly), upper leg (still slower).

Care and nursing education is based on: 1. Providing insulin, 2. Diet, 3. Corporal activity, 4. Blood glucose monitoring, 5. Maintaining personal hygiene-care for the feet, 6 . Monitoring vital signs.

- Providing insulin: All insulin preparations, which are currently in use, should be administered in the form of subcutaneous (subcutaneous) injections with the 45 "angle on the outer (lateral) side of the thigh, both at the front and the front, on the abdominal wall and in gluteus or intravenous infusion, there is no insulin for oral use (by mouth) because if insulin is taken through the mouth to the stomach and the intestine is decomposed like any other protein. Insulin 
preparations are distinguished from each other by: time, moment of injection under the skin until the beginning of their action and duration of the action.

- Diet: The diet of a child with melite diabetes should be such that it contains $50-60 \%$ of carbon hydrate, $25-30 \%$ of fats and $15-20 \%$ of protein and the content of minerals, vitamins and oligoelements. In addition to the three main food rations (morning, lunch, dinner), the child should also take two or three small rations (at 10.17 and 21).

- Corporal activity: With activity it is possible that glucose under the action of insulin is faster and easier to use by the cells. The diabetic diabetes child should deal with common physical and sports activities like all his peers in a community (except for swimming, motoring, parachuting).

- Blood glucose monitoring: Glycemia should be measured 6-7 times per $24 \mathrm{~h}$ for the purpose of changing insulin doses to have a better control of the disease. The test for the use of insulin, the use of gleukometers, where the finger is first disinfected with alcohol and then needle-drilling, the first blood outlet is always removed and the second blood test is performed on the glukometric bar. The most accurate moments for measuring glycemia are bread, before the three meals, two hours after the meal and before bedtime.

- Maintaining personal hygiene-care for the feet: Patients with DM to prevent the appearance of the diabetic foot should undertake the following care. Handkerchiefs and shoes should be 1-2 bigger midsoles, should be checked for the presence of foreign trousers, socks should be cotton, should not be worn with synthetic socks at the knee level because they hinder the circulation and should not wear the shoe. Care of the nails, before the nails are cut out, should be washed with warm water for 15 minutes. The nails are cut right, adjusted with side lime. General Information: Never walk barefoot, do not use creams and solutions without a doctor's description, do not let your feet burn in the sun and do not stand crossed.

- Monitoring vital signs: Hypotension and tachycardia are present in hypothetical monitoring of hypovolemia, hypovolaemia estimates should be made, respiratory type - acetone is due to acetic acid acid disruption and should be reduced as corrected ketosis, dry mouth, augmentation but appetite associated with weight loss, fatigue more than usual, stomach pain, blurred vision, lack of concentration, numbness of the hands or feet, changing temperature, skin color and moisture-fever and chills are common with the infectious process and dehydration occurs.

\section{PURPOSE OF THE STUDY}

- Accounting of the total number of patients with Diabetes Mellitus typel placed in the endocrinology ward, in the Pediatric Clinic in Prishtina, during the 5 year period from 2012 -2016,

- Study of cases of diabetes mellitus type 1 by age groups,

- Study of cases of diabetes mellitus type 1 by gender,

- Study of cases affected by type 1 diabetes mellitus and variations of results,

- Widespread knowledge of the disease, its etiology and its treatment,

- Nursing care and education in patients with type 1 diabetes mellitus.

\section{HYPOTHESIS}

- The general knowledge about diabetes mellitus type 1,

- Nursing education and care for children affected by type 1 diabetes mellitus, in improving and relieving the disease. 


\section{RESEARCH QUESTIONS}

- The research questions were focused on:

- Finding the total number of patients with Diabetes Type 1 Mellitus placed in the Department of Endocrinology at the Pediatric Clinic in Prishtina during the 5 year period from 2012 -2016,

- Number of type 1 diabetes cases by age groups,

- Number of type 1 diabetes cases by gender,

- Number of cases affected by type 1 diabetes based on residence and variations in results

\section{MATERIALS AND METHODOLOGY}

The study is retrospective for all patients treated in 2012-2016. The data for this research were collected from the Patient Clinic Protocol in Prishtina. The data was processed and generated in tabular and graphical form through the microsoft EXCEL application

\section{RESULTS}

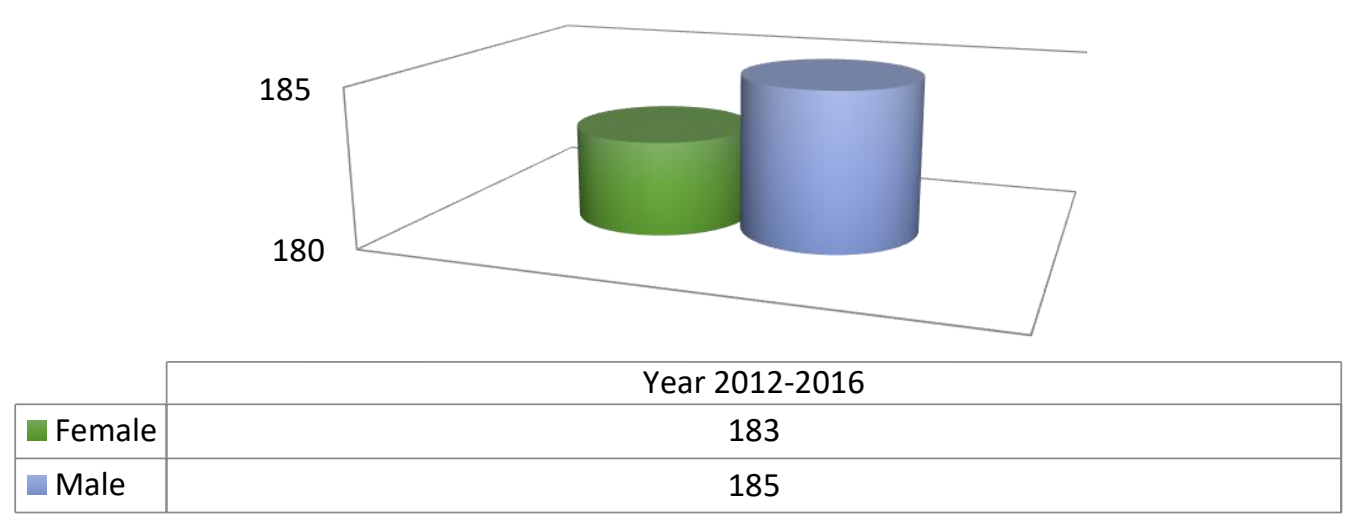

Chart number 1. In the Department of Endocrinology at the Pediatric Clinic in Pristina, children diagnosed with Type 1 diabetes were examined, out of a total of 368 patients, 183 were female and 185 were males. 


\begin{tabular}{|l|l|l|l|l|}
\hline Year & Male & $\%$ & Female & $\%$ \\
\hline $\mathbf{2 0 1 2}$ & 27 & $43.55 \%$ & 35 & $56.45 \%$ \\
\hline $\mathbf{2 0 1 3}$ & 37 & $51.39 \%$ & 35 & $48.61 \%$ \\
\hline $\mathbf{2 0 1 4}$ & 42 & $52.50 \%$ & 38 & $47.50 \%$ \\
\hline $\mathbf{2 0 1 5}$ & 38 & $52.05 \%$ & 35 & $47.95 \%$ \\
\hline $\mathbf{2 0 1 6}$ & 41 & $50.62 \%$ & 40 & $49.38 \%$ \\
\hline Total & 185 & & 183 & \\
\hline
\end{tabular}

Table number 1. Cases presented on the basis of sex in years.

\begin{tabular}{|l|l|l|l|l|l|l|l|l|l|l|}
\hline Year & \multicolumn{2}{|l}{$\mathbf{2 0 1 2}$} & \multicolumn{2}{l}{$\mathbf{2 0 1 3}$} & $\mathbf{2 0 1 4}$ & \multicolumn{2}{l|}{$\mathbf{2 0 1 5}$} & \multicolumn{2}{l|}{2016} \\
\hline Female & $\mathrm{Nr}$ & $\%$ & $\mathrm{Nr}$ & $\%$ & $\mathrm{Nr}$ & $\%$ & $\mathrm{Nr}$ & $\%$ & $\mathrm{Nr}$ & $\%$ \\
\hline $\begin{array}{l}\text { Rural } \\
\text { areas }\end{array}$ & 10 & $28.57 \%$ & 13 & $37.14 \%$ & 14 & $36.84 \%$ & 7 & $20.00 \%$ & 18 & $45.00 \%$ \\
\hline $\begin{array}{l}\text { Urban } \\
\text { areas }\end{array}$ & 25 & $71 \%$ & 22 & $62.86 \%$ & 24 & $63.16 \%$ & 28 & $80.00 \%$ & 22 & $55.00 \%$ \\
\hline Total & 35 & $100.00 \%$ & 35 & $100.00 \%$ & 38 & $100.00 \%$ & 35 & $100.00 \%$ & 40 & $100.00 \%$ \\
\hline Male & $\mathrm{Nr}$ & $\%$ & $\mathrm{Nr}$ & $\%$ & $\mathrm{Nr}$ & $\%$ & $\mathrm{Nr}$ & $\%$ & $\mathrm{Nr}$ & $\%$ \\
\hline $\begin{array}{l}\text { Rural } \\
\text { areas }\end{array}$ & 6 & $22.22 \%$ & 6 & $16.22 \%$ & 13 & $30.95 \%$ & 8 & $21.05 \%$ & 21 & $51.22 \%$ \\
\hline $\begin{array}{l}\text { Urban } \\
\text { areas }\end{array}$ & 21 & $77.77 \%$ & 31 & $83.78 \%$ & 29 & $69.05 \%$ & 30 & $78.95 \%$ & 20 & $48.78 \%$ \\
\hline Total & 27 & $100.00 \%$ & 37 & $100.00 \%$ & 42 & $100.00 \%$ & 38 & $100.00 \%$ & 41 & $100.00 \%$ \\
\hline
\end{tabular}

Table number 2. Number of cases diagnosed with type 1 diabetes mellitus in the Pediatric Clinic based on settlements for 5 years analyzed. 


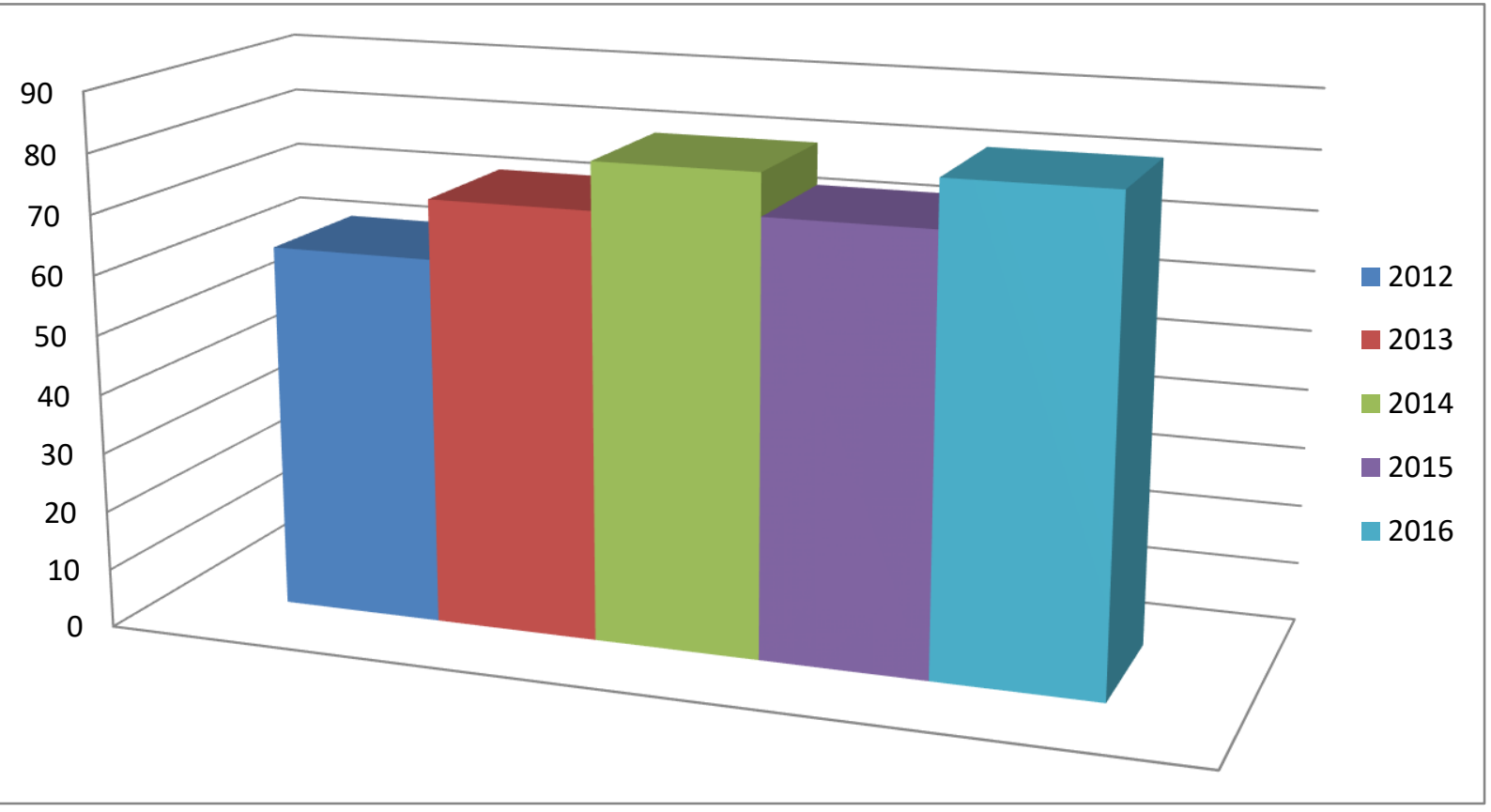

Chart number 2. The table and graph shown above shows the number of cases of type 1 diabetes mellitus for each year from 2012 to 2016. In 2012 we have a total of 62 cases with diabetes mellitus type 1, then in 2013 there are 72 cases with this diagnosis, in 2014 there are a total of 80 cases, in there are 73 cases in 2015 and in 2016 there are currently 81 cases affected by this disease. The results show that there is a fluctuation of the cases presented from year to year where the highest cases are in 2016.

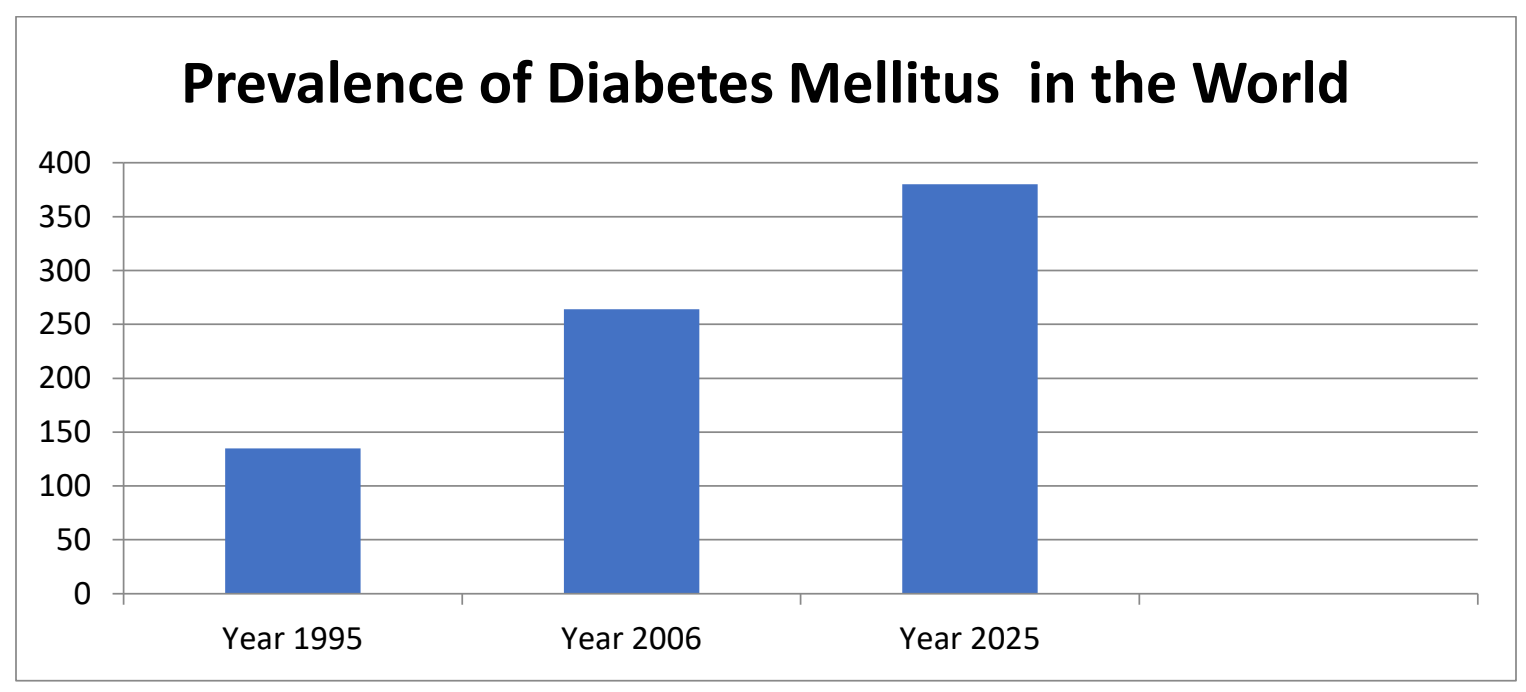

Chart number 3. If we were to make a comparison of this data, we would have the Prevalence of Diabetes mellitus in the World by WHO, with a 2-6\% incidence in Western countries and the highest in other ethnicities. Hyperglycemia is rare in newborns (1\% before 15 years) but its frequency increases with age (7\% after 65 years). The ratio between sexes is roughly the same, affecting every age but with greater frequency ages over ages 45. In 1995 diabetics were 135 million, in 2006 were 264 million but alarming is that it is predicted that in 2025 we will have 380 million diabetics. Type 1 diabetes affects 11 to 22 million people worldwide. 


\section{DISCUSSION}

As can be seen from the results of the study, the number of people with type 1 diabetes mellitus in the Pediatric Clinic in Pristina is 368 patients, of whom 183 are female and 185 are males. So diabetes mellitus type 1 affects almost the same gender, where their percentage is almost halved. In women, the percentage is $49.97 \%$ and in men it is $50.03 \%$. It belongs to the year of birth of children with type 1 diabetes mellitus in females varies between 2001 and 2015. Where 2001 and 2005 are most affected with a higher rate of diabetes, while in men it differs in periods from 2005 until 2016. Where since 2005 we have an increase in the number of patients affected with type 1 diabetes mellitus. The table on male gender by dwelling place shows that the most affected cases are urban areas, where the affected are almost three times more than rural areas, for 2012, 2013, 2014 and 2015, except in 2016 have similar numbers of cases in urban and rural areas. Where in the city we have 131 cases for five years, while in rural areas we have 54 patients. The graph shows us a figure fluctuation year-on-year, with the highest rates being in 2016. As seen from the table, cases have always been increasing, while the female shows the incidence according to settlements from 2012-2016 where even in this case the urban area is more affected than the rural one. In urban areas we have 121 cases and in rural areas we have 62 cases. The peak of new cases is in 2016 with 40 new cases. The prevalence of type 1 diabetes in Kosovo for the last 5 years. The table and graphs shown above show the number of type 1 diabetes cases per year from 2012 to 2016. In 2012 we have a total of 62 cases of type 1 diabetes mellitus, then in 2013 there are 72 cases with this diagnosis, in 2014 there are a total of 80 cases, in 2015 are presented 73 cases and in 2016 there are 81 cases affected by this disease. The results show that we have a fluctuation of results from year to year, where the highest cases are in 2016.

\section{CONCLUSION}

Diabetes screening is the key to preventing complications, early diagnosis, helps preventative complications. Periodic control of glucose reduces complications of hyperglycemia. In patients with type 1 diabetes mellitus, intensive insulin therapy has beneficial effects on reducing the risk of cardiovascular disease. Blood pressure control reduces the risk of cardiovascular, exkemias, hemorrhagic diseases. Any reduction of $10 \mathrm{mmHg}$ of TA reduces with $12 \%$ complications. Patients with diabetes should have special care to protect themselves from infections because they seriously affect diabetes. Protection is achieved simply through three precautionary measures:

First: respecting the rules of body hygiene, protection from moisture and cold.

Second: Regular vaccination against all infectious diseases, including the flu.

Third: Regular and meticulous treatment of diabetes, maintaining its constant balance.

When the patient is affected by various infections, serious antibiotic treatment should be performed. Those who are treated with insulin should increase their dose, while those who are given oral or dietary medication may need to temporarily start insulin treatment. A person with type 1 diabetes mellitus should be informed about the treatment of the disease and the importance of his treatment. For insulin, there must be a medical staff to teach the patient the places where injections of insulin are in the abdomen, thigh, and forearm skin. The injection angle is $45-90^{\circ}$, whereby the skin is initially withdrawn and then injected. It is advisable for patients not to rub the injection site. Also in small children, or elderly, family members are instructed. Patients are given insulin types, meals when used. Hyperglycemia and hypoglycaemia are known and the measures to be taken. Insulin storage is done in a refrigerator, but injection of cold insulin is painful, so it is recommended to keep it at room temperature, but not over 25-50 degrees. The amount of storage is kept in the refrigerator at $2-8^{\circ} \mathrm{C}$, avoiding freezing because it can damage insulin. 


\section{References}

1. Azemi M, Jaha V. Pediatria dhe Kujdesi Infermieror: për studentët e Infermierisë dhe mamisë. Prishtinë: Olymp, 2016

2. Cakerri L, Nanushi M. Bazat e Fiziologjisë të njeriut .

3. Ceka Xh. Histologjia - Tirane 2005

4. Ekoe J, Zimmet P, Williams R, -The epidemiology of diabetes an international perspective, ISBN:0-471-97448-X. C2001

5. Kozdine D. Patologjia morfologjike -.Triptik 2006

6. Lebovitz H. Therapy for diabetes mellitus and related 1disordes. ISBN: 0-945-448-94-5. C1998

7. Llano Y. Dietologji. Triptik 2006

8. Mandro F, Zahaj M, Stefoni S. Bazat e farmakologjisë klinike. ISBN:99927-35-61-9. C2011. Tiranë.

9. Ralton B. Exercise\&disease management of diabetes. ISBN978-1- 4398-2579-8.C2011

10. Remuzzi R. Nephropathy of tape 2 diabetes mellitus, J AM Soc Nephrol 1998

11. Saliaj A. Pediatria - ISBN: 978-99956-91-28-8

12. Saracini E, Saracini H. Anatomia dhe Fiziologjia e njeriut. Prishtinë; 2001

13. Ogden A. Practical Insuline. - ISBN: 978-1-580-40-447-1. (C2011 